\title{
COMPLEXIDADE DA DOCÊNCIA NO INÍCIO DA CARREIRA: as percepções de professores iniciantes na educação básica
}

\author{
Hugo Norberto Krug ${ }^{1}$ \\ Marilia de Rosso Krug ${ }^{2}$ \\ Rodrigo de Rosso $\mathrm{Krug}^{3}$ \\ Moane Marchesan $\mathrm{Krug}^{4}$
}

\begin{abstract}
RESUMO
Este estudo objetivou analisar a complexidade da docência no início da carreira nos Anos Finais do Ensino Fundamental, nas percepções de professores de Educação Física (EF) iniciantes na Educação Básica (EB) de uma rede de ensino pública de uma cidade do interior do estado do Rio Grande do Sul (Brasil), enfatizando o seu papel/função de professor, os seus desafios e os seus sentimentos. Os procedimentos metodológicos foram caracterizados por ser uma pesquisa qualitativa do tipo estudo de caso. O instrumento de pesquisa utilizado para a coleta de informações foi um questionário com perguntas abertas. A interpretação das informações foi realizada por meio da análise de conteúdo. Participaram cinco professores de EF iniciantes na EB das referidas rede e cidade. Concluímos que a docência no início da carreira nos Anos Finais do Ensino Fundamental, nas percepções dos professores de EF iniciantes na EB estudados, mostrou uma realidade educacional complexa, pois apontou papéis/funções, desafios e sentimentos bem diversificados e, por vezes, contraditórios, o que dificulta a fase de entrada na carreira.
\end{abstract}

Palavras-chave: educação física. professores iniciantes. complexidade da docência.

\begin{abstract}
This study was aimed to analyze the complexity of teaching at the beginning of the career in the Final Years of Elementary School, in the perception of Physical Education (PE) teachers who are beginners in Basic Education (BE) of a public education network of a city in the interior of the state of Rio Grande do Sul (Brazil), emphasizing their role/function as a teacher, their challenges and their feelings. The methodological procedures were characterized as a qualitative case study. The research instrument used to collect information was a questionnaire with open questions. The interpretation of the information was carried out through content analysis. Five PE beginning teachers in BE of the referred network and city participated in the study. We conclude that the teaching at the beginning of a career in the Final Years of Elementary School, in the perceptions of PE teachers beginning in BE studied, showed a complex educational reality, as it pointed out roles/functions, challenges and feelings that were quite diverse and, at times, contradictory, which makes it difficult to enter the career stage.
\end{abstract}

Keywords: physical education. beginning teachers. complexity of teaching.

\footnotetext{
${ }^{1}$ Doutor em Educação (UNICAMP/UFSM); Doutor em Ciência do Movimento Humano (UFSM); Professor Aposentado do Departamento de Metodologia do Ensino do Centro de Educação da Universidade Federal de Santa Maria (UFSM); hnkrug@bol.com.br.

2 Doutora em Educação em Ciências: Química da Vida e Saúde (UFSM); Professora Adjunta do Programa de Pós-Graduação em Atenção Integral à Saúde (Mestrado) da Universidade de Cruz Alta (UNICRUZ); mkrug@unicruz.edu.br.

${ }^{3}$ Doutor em Ciências Médicas (UFSC); Professor Adjunto do Programa de Pós-Graduação em Atenção Integral à Saúde (Mestrado) da Universidade de Cruz Alta (UNICRUZ); rodkrug@,bol.com.br.

${ }^{4}$ Doutora em Educação Física (UFSC); Professora Adjunta do Departamento de Humanidades e Educação e Professora Tutora do Programa de Pós-Graduação Multidisciplinar em Saúde da Família da Universidade Regional do Noroeste do Estado do Rio Grande do Sul (UNIJUÍ); moane.krug@unijui.edu.br.
} 


\section{AS CONSIDERAÇÕES INICIAIS}

Segundo Rezer; Madela e Dal-Cin (2016, p. 65), o início da carreira docente “[...] representa um tema complexo [...] e por isso [...] vêm ganhando espaço nos periódicos nacionais [...]” (KRUG et al., 2019a, p. 23), e, nesse cenário, apontamos as seguintes pesquisas: Conceição et al. (2014); Medeiros et al. (2014); Conceição et al. (2015); Quadros, L. et al. (2015); Quadros, Z. et al. (2015); Santos et al. (2016); Krug (2017); Krug et al. (2017a); Krug et al. (2017b); Krug et al. (2017c); Krug (2019a); Krug; Krug (2019); Krug et al. (2019a); Krug (2020b); e, Krug (2020c).

Entretanto, mesmo frente a esse quadro de intensificação de pesquisas, de acordo com Rezer; Madela e Dal-Cin (2016, p. 65), “[...] ainda tem muito a ser pesquisado [...]”, pois o início da carreira docente "[...] se constitui como espaço e tempo de provação que, sem dúvida, irá se desdobrar em influências das mais diversas ao longo de toda carreira docente do professor [...]".

Assim, para Kaefer; Bossle e Fonseca (2016, p. 157-158), “pesquisar esses professores (iniciantes) é uma tentativa de compreender como se constituem suas identidades profissionais docentes e que elementos são mais significativos nesse processo [...]" (inserção nossa).

Neste cenário, mencionamos Huberman (1995) que coloca que, na carreira docente duas situações (denominadas de estágio) podem acontecer com os professores em início de carreira: a) a sobrevivência que se traduz no choque do real, em que o professor inicia um tatear constante com as situações que lhe são apresentadas, preocupando-se consigo mesmo, buscando suportar a distância entre o ideal e o real; e, b) a descoberta que traduz o entusiasmo inicial, o ser professor naquele lugar, assumir responsabilidades com os alunos, com a instituição de ensino, com os demais docentes. Esse autor ainda afirma que, os estágios de sobrevivência e de descoberta ocorrem simultaneamente e que a descoberta fornece condições para a sobrevivência. Destaca que, existem casos de professores iniciantes em que um desses perfis se sobressai em relação ao outro (sobreviver ou descobrir), sendo um desses o dominante.

Diante deste contexto, emergiu o tema 'a complexidade da docência no início da carreira de professores de Educação Física (EF) na Educação Básica (EB)', pois, de acordo com Cardoso (2020, p. 187), nas pesquisas sobre a 
considerando que este é um período marcado pela passagem da condição de aluno para professor e que representa a primeira etapa da carreira docente.

Também Lima (2006) vai neste direcionamento de pensamento ao apontar a necessidade da investigação de aspectos relativos à etapa de iniciação na carreira docente, pois essa etapa é a mais importante do percurso profissional, sendo ao mesmo tempo a mais complexa, uma vez que é marcada por momentos de angústias e de questionamentos diante de uma fase cheia de novidades.

Assim, embasando-nos nestas premissas anteriormente descritas, formulamos a seguinte questão problemática, norteadora do estudo: qual é a complexidade da docência no início da carreira nos Anos Finais do Ensino Fundamental, relativamente ao papel/função de professor, os desafios e os sentimentos vivenciados na docência, nas percepções de professores de Educação Física (EF) iniciantes na Educação Básica (EB), de uma rede de ensino pública, de uma cidade do interior do estado do Rio Grande do Sul - RS (Brasil)?

A partir desta indagação, o estudo teve como objetivo geral analisar a complexidade da docência no início da carreira nos Anos Finais do Ensino Fundamental, nas percepções de professores de EF iniciantes na EB, de uma rede de ensino pública, de uma cidade do interior do estado do RS (Brasil), enfatizando o seu papel/função de professor, os seus desafios e os seus sentimentos.

Em decorrência deste objetivo geral, buscamos atingir os seguintes objetivos específicos: 1) analisar o papel/função do professor de EF na docência nos Anos Finais do Ensino Fundamental, nas percepções de professores de EF iniciantes na EB, de uma rede de ensino pública, de uma cidade do interior do estado do RS (Brasil); 2) analisar os desafios do professor de EF na docência nos Anos Finais do Ensino Fundamental, nas percepções de professores de EF iniciantes na EB, de uma rede de ensino pública, de uma cidade do interior do estado do RS (Brasil); e, 3) analisar os sentimentos vivenciados pelo professor de EF na docência nos Anos Finais do Ensino Fundamental, nas percepções de professores de EF iniciantes na EB, de uma rede de ensino pública, de uma cidade do interior do estado do RS (Brasil).

Justificamos a realização deste estudo pela tentativa de compreender a complexidade da docência pertinente aos professores de EF iniciantes na EB. Dessa forma, a expectativa foi de que o estudo trouxesse significativas contribuições para a compreensão do fenômeno INÍCIO DA DOCÊNCIA, e que favorecesse a concretização da melhoria da qualidade da inserção na escola de professores de EF iniciantes na EB. Nesse sentido, é importante mencionarmos Luft (2000) que afirma que, a palavra complexidade significa qualidade de 
complexo. Complexo é o que abrange muitas coisas ou grande número de partes de uma coisa, é algo complicado.

\section{OS PROCEDIMENTOS METODOLÓGICOS}

Considerando que, segundo Krug et al. (2015, p. 120), “[...] os procedimentos metodológicos manifestam a intencionalidade e os pressupostos teóricos dos pesquisadores [...]", caracterizamos esta investigação como uma pesquisa qualitativa do tipo estudo de caso.

Neste sentido, citamos Goldenberg (1997) que afirma que, na pesquisa qualitativa o pesquisa não se baseia na representatividade numérica do grupo, mas na compreensão aprofundada de um grupo social, de uma organização, de uma instituição, de uma trajetória. Já, de acordo com Alves-Mazzotti (2006), o estudo de caso é o tipo de pesquisa desenvolvido em apenas uma unidade (por exemplo, uma instituição de ensino, uma rede de ensino, etc.) ou apresenta um número reduzido de participantes, sem explicitar porque foi escolhida aquela unidade e não outra, deixando a impressão de que poderia ser qualquer uma. Assim, neste estudo, o caso investigado referiu-se aos professores de EF iniciantes na EB, de uma cidade do interior do estado do RS (Brasil).

Desta forma, a justificativa da escolha da forma de pesquisa qualitativa e estudo de caso foi devido "[...] à possibilidade de se analisar um ambiente em particular, onde se levou em conta o contexto social e sua complexidade para compreender e retratar uma realidade em particular e um fenômeno em especial [...]" (KRUG et al., 2017b, p. 59-60), 'as percepções de professores de $\mathrm{EF}$ iniciantes na $\mathrm{EB}$, sobre a complexidade da docência no início da carreira'.

$\mathrm{O}$ instrumento de pesquisa foi um questionário com perguntas abertas. Justificamos a escolha desse instrumento de pesquisa embasando-nos em Aragão e Moretti-Pires (2012) que dizem que, o questionário é um instrumento que pode ser utilizado, tanto na pesquisa quantitativa, quanto na qualitativa. Já, perguntas abertas "destina-se a obter uma resposta livre" (CERVO; BERVIAN, 1996, p. 138).

Como procedimento de elaboração do instrumento, todas as questões foram construídas, a partir do problema de pesquisa, levando em consideração o objetivo geral da investigação. As questões norteadoras que compuseram o questionário estavam relacionadas com os objetivos específicos desta investigação e foram as seguintes: 1) na sua percepção, qual é o papel/função do professor de Educação Física, no seu caso iniciante na carreira, na docência nos Anos Finais do Ensino Fundamental? 2) na sua percepção, quais foram os desafios (problemas/dificuldades) enfrentados durante a docência (no início da carreira) nos Anos Finais do Ensino Fundamental? e, 3) na sua percepção, quais foram os sentimentos 
vivenciados durante a docência (no início da carreira) nos Anos Finais do Ensino Fundamental?

A interpretação das informações coletadas, pelo instrumento de pesquisa, foi realizada por meio da análise de conteúdo, que, para Turato (2003), possui os seguintes procedimentos básicos: a leitura flutuante, o agrupamento das respostas e a categorização. Conforme Franco (2012, p. 63), as categorias correspondem a "uma operação de classificação de elementos constitutivos de um conjunto, por diferenciação seguida de um reagrupamento baseado em analogia, a partir de critérios definidos".

Já, Minayo; Deslandes e Gomes (2007) colocam que, a(s) categoria(s) pode(m) ser gerada(s) previamente à pesquisa de campo. Assim, neste estudo, foram considerados como categorias prévias, o papel/função do professor de EF, os desafios enfrentados na docência e os sentimentos vivenciados na docência, isto é, os objetivos específicos do estudo. Entretanto, a partir das respostas dos participantes ao instrumento de pesquisa foram levantadas as unidades de significados (unidades de registro), considerando os pontos singulares e comuns sobre os elementos que correspondiam ao objeto do estudo. Nesse sentido, Molina Neto (2010) esclarece que, unidades de significados são como enunciados dos discursos do informante que são significativos tanto para o colaborador (pesquisado) como para o pesquisador, sendo atribuído aos pressupostos teóricos da pesquisa.

Participaram deste estudo, como colaboradores, cinco professores de EF iniciantes na EB, de uma rede de ensino pública, de uma cidade do interior do estado do RS (Brasil).

Assim, no quadro 1, apresentamos alguns dados de identificação dos colaboradores do estudo.

Quadro 1 - Algumas informações a cerca dos professores colaboradores da pesquisa.

\begin{tabular}{|c|c|c|c|c|c|}
\hline Professor & Idade & Sexo & Estado Civil & Formação & Rede de Ensino \\
\hline 1 & 20 & Feminino & Solteira & Licenciada em EF & Municipal \\
\hline 2 & 25 & Masculino & Solteiro & Licenciado em EF & Municipal \\
\hline 3 & 22 & Feminino & Solteira & Licenciada em EF & Municipal \\
\hline 4 & 23 & Feminino & Solteira & Licenciada em EF & Municipal \\
\hline 5 & 28 & Masculino & Casado & Licenciado em EF & Municipal \\
\hline
\end{tabular}

Fonte: Os autores.

A partir das informações do quadro 1, convém esclarecermos que a idade, o sexo e o estado civil não foram objeto deste estudo, bem como que, para participarem deste estudo, os colaboradores possuíam até três anos de docência na escola, conforme preconiza Huberman (1995). 
A escolha dos participantes (colaboradores) aconteceu de forma intencional, pois estes cinco professores de EF eram os únicos iniciantes da rede de ensino e cidade estudada, sendo então, selecionados pela representação tipológica, segundo Molina Neto (2010).

A respeito dos aspectos éticos vinculados às pesquisas científicas, ressaltamos que todos os envolvidos assinaram o Termo de Consentimento Livre e Esclarecido e suas identidades foram preservadas (numerados de 1 a 5 ).

\section{OS RESULTADOS E AS DISCUSSÕES}

Os resultados e as discussões deste estudo foram orientados e explicitados tendo como referência os seus objetivos específicos.

\section{O papel/função do professor de Educação Física na docência nos Anos Finais do Ensino} Fundamental, nas percepções dos professores de Educação Física iniciantes na

\section{Educação Básica estudados}

Segundo Luft (2000), a palavra função significa obrigação a cumprir, papel a desempenhar. O autor ainda afirma que, o conceito de papel está associado à função desempenhada por alguém ou algo. Acrescenta que, as palavras função e papel são sinônimos.

Neste sentido, podemos salientar que, as diferentes correntes de pensamentos sobre o processo de ensinar e aprender acaba dando condições dos professores atribuírem um sentido particular e, ao mesmo tempo, complementar e abrangente a respeito do papel/função do professor (KRUG, 2018).

Assim, as análises das informações com os professores de EF iniciantes na EB, demonstraram o quanto é diversificado, abrangente e complementar o entendimento deles a respeito do papel/função do professor de EF nos Anos Finais do Ensino Fundamental. As várias expressões utilizadas para descrever o papel/função do professor foram interpretadas constituindo-se 'três unidades de significados' denominadas a seguir: a) 'contribuir na formação da cidadania dos alunos'; b) 'ser educador'; e, c) ‘transmitir conhecimentos'.

Desta forma, o principal papel/função do professor de EF na docência nos Anos Finais do Ensino Fundamental, nas percepções dos professores de EF iniciantes na EB estudados, foi 'contribuir na formação da cidadania dos alunos' (três citações - Professores: 2; 3; e, 5). Esse papel/função pode ser fundamentado em Ilha; Ivo e Krug (2007) que colocam que, a EF, como disciplina obrigatória do currículo escolar, deve participar do processo de construção do cidadão, visto que, tem potencial efetivo para influenciar significativamente a vida dos jovens. Já, Marques et al. (2009, p. 1) reforçam esse entendimento apontando que, a EF está inserida 
no currículo escolar “[...] com a intenção de educar o aluno, através da construção de valores, auxiliando no desenvolvimento de suas potencialidades motoras, cognitivas, afetivas, sociais, bem como na formação de bons cidadãos”. Nessa mesma direção de pensamento, citamos Souza (2012, p. 241) que diz que, "a Educação Física é um componente essencial na construção da cidadania, na medida em que seu objeto de estudo é a produção cultural da sociedade através do movimento humano". Assim, esse fato está em consonância com o estudo de Krug (2019c, p. 5) que constatou a existência de "[...] contribuições da EF para a construção da cidadania dos alunos [...]" da EB, nas percepções de professores da área. Além disso, Krug et al. (2018, p. 57) constataram que, a “[...] cidadania [...]" é uma das representações sociais da EF Escolar de professores de EF da EB.

Outro papel/função do professor de EF na docência nos Anos Finais do Ensino Fundamental, nas percepções dos professores de EF iniciantes na EB estudados, foi 'ser educador' (uma citação - Professor: 1). Relativamente a esse papel/função nos dirigimos a Behrens (2003) que afirma que, é indispensável que o professor tenha consciência de que seu papel é ser educador. Seu papel envolve não somente o conhecimento técnico e específico da área, como também o de ser professor, aliado ainda à formação de seres humanos, com valores, atitudes, ética e postura profissional. Segundo Luckesi (1992), o professor educador é aquele que tendo adquirido o nível de cultura necessária para o desempenho de sua função, dá direção ao ensino e à aprendizagem. Ele assume o papel de mediador entre a cultura elaborada, acumulada e em processo de acumulação pela humanidade e o educando. $\mathrm{O}$ professor deverá fazer a mediação entre os resultados da cultura, ou seja, o coletivo da sociedade e o individual do aluno. O seu papel é o de mediador social entre o universo da sociedade e o particular do educando. Para que possa exercer sua função, o professor deve possuir conhecimentos e habilidades suficientes para poder auxiliar o aluno no processo de elaboração cultural.

'Transmitir conhecimentos' (uma citação - Professor: 4) foi mais outro papel/função do professor de EF na docência nos Anos finais do Ensino Fundamental, nas percepções dos professores de $\mathrm{EF}$ iniciantes na $\mathrm{EB}$ estudados. A respeito deste papel/função nos referimos a Gauthier et al. (1998) que afirmam que durante muito tempo pensou-se, e muitos, sem dúvida, ainda pensam assim, que ensinar consiste em transmitir um conteúdo a um grupo de alunos. $\mathrm{O}$ autor acrescenta que pensar assim é reduzir uma atividade tão complexa quanto o ensino a uma única dimensão, aquela que é mais evidente, mas, sobretudo, negar-se a refletir de forma mais profunda sobre a natureza desse ofício e dos outros saberes que lhe são necessários. Já Tardif (2002, p. 31) destaca que, o educador "é alguém que sabe alguma coisa e cuja função 
consiste em transmitir esse saber aos outros". Entretanto, esse autor alerta que, a função do professor não se reduz à transmissão de saberes constituídos. Além disso, ele está envolvido com saberes curriculares, disciplinares, experenciais e de sua formação profisssional. Nesse cenário, Freire (1996) destaca que, ensinar não é transmitir conhecimentos, mas possibilidades para a sua própria produção ou construção.

Assim, estes foram os papéis/função do professor de EF na docência nos Anos Finais do Ensino Fundamental nas percepções dos professores de EF iniciantes na EB estudados.

Após relatarmos e analisarmos os papéis/função do professor de EF na docência nos Anos Finais do Ensino Fundamental, nas percepções dos professores de EF iniciantes na EB estudados, constatamos que, são diversos, ocasionando assim, dificuldades aos professores na compreensão e execução da atividade docente.

Ao elaborarmos uma 'análise geral' sobre as percepções dos professores de EF iniciantes na EB estudados, a respeito dos papéis/funções do professor de EF na docência nos Anos Finais do Ensino Fundamental contatamos que, a 'quase totalidade' (Professores: 1; 2; 3; e, 4) pode ser classificado em uma visão de EF Escolar e do papel/função do professor de EF numa 'educação considerada como transformadora do status quo da sociedade vigente'. Segundo Luckesi (1992), a educação transformadora é aquela que pretende demonstrar ser possível a educação dentro da sociedade, com seus determinantes e condicionantes, mas com a possibilidade de trabalhar pela sua democratização. Em relação à EF transformadora, de acordo com Medina (1983), essa tendência critica a concepção orgânica e biológica do movimento humano e considera-o como um fato cultural. Nessa concepção, a EF torna-se uma área de conhecimento responsável pelo estudo a cerca dos aspectos antropológicos do movimento humano, procurando despertar a consciência corporal não apenas em seus aspectos biológicos e psicológicos, mas a respeito do significado simbólico do movimento corporal humano. Já, uma 'pequena parcela' (Professor: 5) dos professores estudados possui uma percepção de EF Escolar e papel/função do professor de EF numa 'educação considerada reprodutora do status quo da sociedade vigente'. Para Luckesi (1992), a educação reprodutora é aquela que concebe a educação como um elemento da sociedade, determinada por seus condicionantes econômicos, sociais e políticos, portanto, a serviço dessa mesma sociedade e de seus condicionantes. Relativamente a EF reprodutora, mencionamos Castro (2010, p. 1) que afirma que, essa é aquela em que "o professor trabalha apenas com movimentos corporais nas suas aulas, sem qualquer relação com o modo de vida dos estudantes, sem nenhuma reflexão [...] sobre esses movimentos, ministrando aulas que valorizam a competição, a concorrência e o rendimento em sua prática". 
Assim, podemos inferir que, as percepções dos professores de EF iniciantes na EB estudados, sobre o papel/função do professor de EF na docência nos Anos Finais do Ensino Fundamental, está sustentado em dois pólos opostos de visão da EF na escola e do papel/função do professor frente ao ensino. Um, tendo a EF como transformadora do status quo da sociedade vigente e, outro, tendo a EF como reprodutora do status quo da sociedade vigente.

Neste sentido, lembramos Ilha; Maschio e Krug (2008) que afirmam que, os papéis/funções exercidos pelo professor trazem em si, concepções, objetivos, visão de homem, de sociedade e mundos próprios, que podem ser conscientes ou inconscientes. Além disso, Darido e Neto (2005, p. 1) dizem que, "quando se conhecem os pressupostos pedagógicos que estão por trás da atividade de ensino, é possível melhorar a coerência entre o que se pensa estar fazendo e o que realmente realizamos". Já, Krug et al. (2015, p. 125) destacam que, "[...] é muito importante que o professor tenha claro para si e para os outros (alunos) o papel/função a ser desempenhado na atividade docente” (inserção nossa).

\section{Os desafios do professor de Educação Física na docência nos Anos Finais do Ensino Fundamental, nas percepções dos professores de Educação Física iniciantes na Educação Básica estudados}

Segundo Lima (2012), o professor, ao mesmo tempo em que se torna o centro dos discursos das reformas educativas e, é considerado fundamental no processo educativo, o sujeito ator e autor imprescindível para a melhoria da qualidade do ensino, também enfrenta, no exercício da docência, vários desafios que dificultam e lhe impedem atingir o sucesso em sua atuação.

Neste cenário, convém lembrarmos Luft (2000) que coloca que, a palavra desafio significa a ação ou efeito de desafiar. É a ocasião de grande obstáculo que deve ser ultrapassado, ou ainda, o ato de instigar alguém para que se realize alguma coisa, normalmente, além de suas competências ou habilidades. Já, Marques et al. (2015, p. 189) consideram que desafio é "a possibilidade de enfrentamento dos problemas e/ou dificuldades definidos(as) como um obstáculo, uma situação difícil ou ainda algo de difícil solução"

Neste sentido, Lima (2012) salienta que, os professores convivem com inúmeros desafios durante a docência e que estes podem ser identificados, e, dessa forma, considerando que, para Ilha e Krug (2016, p. 181), “a entrada na carreira representa um desafio para o professor, tendo em vista sua inexperiência vivencial cotidiana no contexto de uma instituição educacional", procuramos identificar e analisar, através das informações coletadas, alguns dos 
desafios que fazem parte da prática cotidiana da docência na EB, nas percepções dos professores de EF iniciantes na EB estudados. Assim, esses se utilizaram de várias expressões para descrever os muitos desafios do cotidiano das aulas, interpretadas constituindo-se 'cinco unidades de significados' a seguir: a) 'as condições de trabalho difíceis'; b) 'o isolamento docente'; c) 'a indisciplina dos alunos'; d) 'a falta de interesse dos alunos pelas atividades propostas'; e) 'a inexperiência profissional'; e, f) ‘a desvalorização da EF na escola'.

Desta forma, a questão das 'condições de trabalho difíceis/precárias', expressas pela falta de espaços físicos e de materiais para as aulas de EF (quatro citações - Professores: 1; 2; 3; e, 5), foi o principal desafio, que se postou no cotidiano educacional dos professores de EF iniciantes na EB estudados. Sobre esse desafio, nos reportamos a Krug (2019a, p. 5) que afirma que, “[...] as condições de trabalho difíceis e falta de espaço físico e materiais para as aulas [...]" é uma das dificuldades encontradas na prática pedagógica de professores de EF iniciantes na EB. Dessa forma, segundo Krug et al. (2017a, p. 18), as condições de trabalho difíceis/precárias é um desafio que “[...] interfere negativamente na prática pedagógica dos professores [...]" de EF iniciantes na EB. Além disso, Krug et al. (2017b, p. 64) destacam que, “as condições de trabalho difíceis/precárias da Educação Física na escola [...]" é uma das marcas docentes negativas apontada por professores de EF iniciantes na EB. Assim, diante desse contexto, Krug; Krug e Krug (2020a, p. 47) colocam que, uma das preocupações pedagógicas de professores de EF iniciantes na EB é “[...] com o espaço físico para a aula" e “[...] com a adaptação das atividades para o ambiente e materiais”. Já Krug et al. (2019a, p. 26) dizem que, “[...] saber dar aula de EF em condições de trabalho difíceis/precárias [...]" é uma das necessidades formativas de professores de EF iniciantes na EB.

O 'isolamento docente' (três citações - Professores: 2; 4; e, 5) foi outro desafio, que se configurou no cotidiano educacional dos professores de EF iniciantes na EB estudados. No direcionamento deste desafio apontamos Krug (2020a, p. 5) que diz que, “[...] o isolamento profissional docente [...]” é uma das dificuldades que os professores de EF iniciantes na EB. Já, de acordo com Krug et al. (2017a, p. 19), “o isolamento docente [...]” é um desafio que “[...] interfere negativamente na prática pedagógica dos professores [...]" de EF iniciantes na EB. Além disso, Krug (1996) destaca que, não se chega a um bom resultado no ensino da EF com professores numa posição de individualismo e de isolamento profissional. Assim, frente a esse cenário, Krug et al. (2019a, p. 27) ressaltam que, saber “[...] compreender as causas e consequências do isolamento docente [...]" é uma das necessidades formativas de professores de EF iniciantes na EB. 
Outro desafio, manifestado no cotidiano educacional dos professores de EF iniciantes na EB estudados, foi a 'indisciplina dos alunos' (três citações - Professores: 1; 3; e, 5) foi outro desafio que se configurou na docência nos Anos Finais do Ensino Fundamental dos professores de EF iniciantes na EB estudados. Em referência a esse desafio citamos Krug (2020a, p. 5) que ressalva que, “[...] a indisciplina dos alunos [...]” é uma das dificuldades que os professores de EF iniciantes na EB enfrentam em sua docência. Já Krug (2019a, p. 6) especifica que, "a indisciplina dos alunos [...]" é uma dificuldade na gestão da aula em todas as fases da carreira docente (entrada; estabilização; diversificação; serenidade e/ou conservantismo; e, desinvestimento). Nesse sentido, Krug et al. (2017a, p. 20) indicam que, "[...] a indisciplina dos alunos [...]" é um dos desafios que "[...] interfere negativamente na prática pedagógica dos professores [...]” de EF iniciantes na EB. Assim sendo, de acordo com Krug et al. (2017b, p. 64), “[...] a indisciplina dos alunos [...]” é uma das marcas docentes negativas apontadas por professores de EF iniciantes na EB. Diante desse quadro descrito, mencionamos Krug; Krug e Krug (2020a, p. 46) que dizem que, uma das preocupações pedagógicas de professores de EF iniciantes na EB é “[...] com o comportamento indisciplinado dos alunos". Além disso, Krug; Krug e Krug (2019) salientam que, os professores de EF iniciantes na EB precisam viabilizar alternativas para o entrave pedagógico que é a indisciplina dos alunos, pois este limita a busca de uma EF de melhor qualidade. Assim, nesse contexto nos reportamos a Krug et al. (2019a, p. 26) que afirmam que, "saber lidar com alunos indisciplinados [...]" é uma das necessidades formativas de professores de EF iniciantes na EB.

A 'falta de interesse dos alunos pelas atividades propostas' (duas citações Professores: 2; e, 4) foi mais um dos desafios da docência nos Anos Finais do Ensino Fundamental que se mostrou no cotidiano educacional dos professores de EF iniciantes na EB estudados. No sentido desse desafio Krug et al. (2019b, p. 231) dizem que, “[...] a falta de interesse dos alunos pelas atividades propostas [...]" é uma das dificuldades pedagógicas de professores de EF na EB em diversas fases da carreira (entrada; estabilização; diversificação; serenidade e/ou conservantismo; e, desinvestimento). Nesse sentido, Krug et al. (2017a, p. 21) salientam que, a falta de interesse dos alunos pelas atividades propostas é um desafio que "[...] interfere negativamente na prática pedagógica dos professores [...]” de EF iniciantes na EB. Além disso, Krug et al. (2017b, p. 66) ressaltam que, “[...] a falta de interesse dos alunos pelas atividades propostas [...]" é uma das marcas docentes negativas apontadas por professores de EF iniciantes na EB. Assim, diante desse contexto, Krug: Krug e Krug (2020a, p. 46) afirmam que, uma das preocupações pedagógicas de professores de EF iniciantes na EB é "[...] se os 
alunos vão gostar das atividades propostas”. Dessa forma, Krug et al. (2019a, p. 26) observam que, "[...] saber lidar com a falta de interesse dos alunos pelas atividades propostas [...]" é uma das necessidades formativas de professores de EF iniciantes na EB.

Ainda outro desafio que se projetou na docência nos Anos Finais do Ensino Fundamental dos professores de EF iniciantes na EB estudados foi a 'inexperiência profissional' (duas citações - Professores: 3; e, 4). Esse desafio encontra suporte em vários estudos (KRUG, 2020a; KRUG, 2019a; KRUG et al., 2019b) que destacam que, a inexperiência profissional docente é uma das dificuldades pedagógicas no cotidiano escolar de professores de EF iniciantes na EB. Já, Krug e Ilha (2016, p. 181) afirmam que, a entrada na carreira "representa um desafio para o professor, tendo em vista a sua importância vivencial cotidiana no contexto da instituição educacional". Salientam que, devido à inexperiência do professor iniciante em relação às vivências do processo de trabalho docente e de lacunas que isto representa para a compreensão deste processo, estes professores, geralmente, os que tiveram pouca ou nenhuma experiência significativa como docente durante a formação inicial, sentem muita dificuldade nesta fase da carreira. Entretanto, "o dia a dia do processo de trabalho docente é que poderão possibilitar ao professor experimentar e compreender toda a complexidade que envolve o ensino, a instituição escolar e os demais elementos micro e macro que compõem a educação" (ILHA; KRUG, 2016, p. 182).

A 'desvalorização da EF na escola' (uma citação - Professor: 1) foi também outro desafio que se encontrou na docência nos Anos Finais do Ensino Fundamental dos professores de EF iniciantes na EB estudados. Em se tratando desse desafio encontramos na literatura especializada que a desvalorização da EF é uma das dificuldades do cotidiano escolar enfrentadas pelos professores de EF iniciantes na EB (KRUG, 2020a; KRUG, 2019a; KRUG et al., 2019b; CONCEIÇÃO et al., 2015). Já, para Krug et al. (2017a, p. 22), a desvalorização da EF na escola é um desafio que “[...] interfere negativamente na prática pedagógica dos professores [...]” de EF iniciantes na EB. Assim, segundo Marques et al. (2015), a desvalorização da EF na escola pode ser considerada um forte empecilho ao trabalho docente. Além disso, Krug et al. (2020) apontam que, nas percepções de professores de EF da EB, todas as fases da carreira docente (entrada; estabilização; diversificação; serenidade e/ou conservantismo; e, desinvestimento) são geradoras de fatores indicativos de desvalorização da EF na EB.

Assim, estes foram os desafios do professor de EF na docência nos Anos Finais do Ensino Fundamental, nas percepções dos professores de EF iniciantes na EB estudados. 
Ao efetuarmos uma 'análise geral' sobre as percepções dos professores de EF iniciantes na EB estudados, relativamente aos desafios dos professores de EF iniciantes na docência nos Anos Finais do Ensino Fundamental constatamos que, uma 'metade' (três do total de seis) dos desafios está 'ligada à estrutura da escola/sistema educacional' ('as condições de trabalho difíceis'; 'o isolamento docente'; e, 'a desvalorização da EF na escola') e uma outra 'metade' (três do total de seis) dividida em duas partes, uma (duas do total de seis) está 'ligada aos alunos da EB' ('a indisciplina dos alunos'; e, 'a falta de interesse dos alunos pelas atividades propostas') e outra parte (uma do total de seis) 'ligada aos próprios professores, ou seja, a si mesmos' ('a inexperiência profissional'). Vale ainda ressaltar que, os desafios do professor de EF nos Anos Finais do Ensino Fundamental, nas percepções de professores de EF iniciantes na $\mathrm{EB}$ estudados, de forma geral, tiveram no total quinze citações, sendo oito 'ligadas à estrutura da escola/sistema educacional', cinco 'ligadas aos alunos da EB' e duas 'ligadas aos próprios professores, ou seja, a si mesmos'. Entretanto, o fato interessante foi que todos os professores estudados apontaram três desafios cada um. A partir dessas constatações, podemos inferir que, de forma geral, os desafios do professor de EF iniciantes nos Anos Finais do Ensino Fundamental estão ligados à diversos fatores, tanto fatores relacionados internamente à prática pedagógica dos professores (aos alunos e aos próprios professores), quanto à fatores relacionados externamente à prática pedagógica dos professores (estrutura da escola/sistema educacional). Esse fato está em consonância com o estudo de Krug et al. (2017a). Além disso, Pimenta (2005) afirma que, o professor é responsável direto pelo processo ensino-aprendizagem que ocorre na sala de aula, ele representa e necessita de uma autonomia didática que se expressa no cotidiano de seu trabalho, assim ele é capaz de enfrentar os desafios do processo ensino-aprendizagem e da educação. Já, Telles et al. (2015, p. 7) apontam que, “[...] saber os desafios da profissão docente [...]" é um dos saberes necessários ao bom professor de EF Escolar.

\section{Os sentimentos expressos pelo professor de Educação Física na docência nos Anos Finais do Ensino Fundamental, nas percepções dos professores de Educação Física iniciantes na Educação Básica estudados}

Segundo Silva e Krug (2004 apud KRUG et al., 2019c, p. 13), “o ofício da docência é fonte de sentimentos, os quais assumem uma importância ímpar, pois o estudo dos mesmos permite o conhecimento dos aspectos peculiares aos docentes que podem interferir direta ou indiretamente no ensino". 
Neste cenário, lembramos Lima (2012) que assinala que a profissão professor tem em si algo ambíguo, pois, mescla diariamente, sentimentos muito diversos. Em um mesmo dia, em uma mesma turma, com um mesmo aluno, o professor vivencia o sentimento de alegria com seu desenvolvimento em uma atividade, mas, de repente, entristece-se com uma atitude dele ou mesmo se revolta com as condições de vida desse aluno.

Já Bianchini et al. (2017) ressaltam que, os sentimentos fazem parte da vida afetiva das pessoas e, portanto, importantes de serem compreendidos, quando se pensa em todos os envolvidos com a escola, uma vez que vivenciados de várias formas nesse contexto e podendo atuar como fonte promotora de ações positivas ou não.

Desta forma, apontamos Luft (2000) que coloca que a palavra sentimento significa o ato ou efeito de sentir(-se); disposição para se comover, se impressionar; sensibilidade.

Assim, as análises das informações coletadas com os professores de EF iniciantes na EB estudados foram interpretadas constituindo-se em 'duas unidades de significados' denominadas a seguir: a) 'sentimentos positivos para com a docência'; e, b) 'sentimentos negativos para com a docência'. Salientamos que, essas unidades de significados foram fundamentadas em Krug et al. (2012b, p. 3) que classificam os sentimentos expressos pelos professores em positivos e negativos. Os “[...] sentimentos positivos são aqueles que se originam do sucesso pedagógico e os sentimentos negativos são aqueles que se originam do insucesso pedagógico".

Desta forma, 'identificamos um rol de quatro sentimentos' vivenciados pelos professores de EF iniciantes na EB estudados, classificados como 'positivos': 'alegria'; ‘ânimo'; 'gratificação'; e, 'satisfação'.

Quanto aos 'sentimentos positivos' constatamos que, a 'alegria' foi o mais citado pelos professores estudados (cinco citações - Professores: 1; 2; 3; 4; e 5). Segundo Luft (2000, p. 23) alegria significa "um contentamento". Nesse sentido, Krug; Krug e Krug (2019, p. 90) destacam que, a “[...] alegria [...]" é um dos sentimentos vivenciados pelos professores de EF da EB em sua docência.

O ‘ânimo' foi o segundo ‘sentimento positivo' mais citado pelos professores estudados (quatro citações - Professores: $1 ; 2 ; 4 ;$ e, 5). Luft (2000) diz que, ânimo é um estado de espírito, vontade, confiança. Assim sendo Krug; Krug e Telles (2019) constataram que, a docência em EF na EB comporta sentimentos de ânimo profissional. Dessa forma, Flores et al. (2010) afirmam que, apesar das dificuldades inerentes à profissão, existem professores animados profissionalmente, interessados em melhorar sua prática pedagógica cada vez mais, pois ao atingirem o sucesso pedagógico sentem-se motivados com a docência. 
O terceiro 'sentimento positivo' mais citado pelos professores estudados (três citações - Professores: 2; 3; e, 4) foi a 'gratificação'. Conforme Luft (2000), gratificação é uma reação emocional em resposta ao cumprimento de um desejo ou objetivo. Nesse sentido, Krug; Krug e Krug (2019) constataram que, a docência em EF na EB comporta sentimentos de gratificação profissional. Já, Krug e Krug (2008, p. 8), a partir do prazer e satisfação o professor passa a ter "[...] uma sensação de gratificação com aquilo que faz".

A 'satisfação' foi o quarto e último 'sentimento positivo' mais citado pelos professores estudados (duas citações - Professores: 4; e, 5). Para Luft (2000), satisfação é a ação ou efeito de satisfazer. É um contentamento, uma alegria. Dessa forma, Krug; Krug e Telles (2019) constataram que, a docência em EF na EB comporta sentimentos de satisfação profissional. Também Krug et al. (2019c) constataram o mesmo fato. Já, Marcolan et al. (2017, p. 89) destacam que, "a satisfação por si só é algo emocionalmente positivo em relação aos objetivos atingidos pelo trabalho desempenhado".

Em relação aos 'sentimentos negativos', 'identificamos um rol de seis': 'insegurança'; ‘insatisfação'; 'impotência'; 'frustração'; 'desânimo'; e, 'raiva’.

Quanto aos 'sentimentos negativos' constatamos que, a 'insegurança' foi o mais citado pelos professores estudados (cinco citações - Professores: $1 ; 2 ; 3 ; 4 ;$ e, 5). De acordo com Luft (2000), insegurança é a falta de segurança; periculosidade. Sensação de não estar seguro. Assim sendo, Krug; Krug e Telles (2019) constataram que, a docência em EF na EB comporta sentimentos de insegurança profissional. Dessa maneira, Flores et al. (2010) colocam que, o sentimento de insegurança de professores de EF na EB aparece, fortemente, a partir das tensões provocadas por certas dificuldades no desenvolvimento da prática pedagógica.

Outro 'sentimento negativo' mais citado pelos professores estudados (quatro citações - Professores: 1; 3; 4; e, 5), o segundo, foi a 'insatisfação’. Para Luft (2000), insatisfação é a falta de satisfação; descontentamento, desprazer. Dessa forma, Krug; Krug e Telles (2019) constataram que, a docência em EF na EB comporta sentimentos de insatisfação profissional. Também Krug et al. (2019c, p. 85) constataram o mesmo fato. Já, Marcolan et al. (2017, p. 85) colocam que, "professor insatisfeito não encontra sentido no que faz e acaba se desmotivando, uma vez que a motivação é algo do ser humano advinda das suas necessidades".

A 'impotência' foi o terceiro 'sentimento negativo' mais citado pelos professores estudados (três citações - Professores: 1; 2; e, 3). Segundo Luft (2000), a impotência é a falta de poder, força ou meios para realizar algo; impossibilidade. Nesse cenário, Krug; Krug e Telles (2019) constataram que, a docência em EF na EB comporta sentimentos de impotência 
profissional. Já Flores et al. (2010) ressaltam que, o professor que não consegue dar conta da variedade e da complexidade da docência sente-se impotente diante das dificuldades da prática pedagógica.

O quarto 'sentimento negativo' mais citado pelos professores estudados (duas citações - Professores: 3; e, 4) foi a 'frustração'. Luft (2000, p.308) diz que, frustração significa “desiludir-se, decepcionar-se”. Nesse sentido, Mattos (1994) aponta que, as frustrações são causas importantes no declínio da motivação, ocasionando conseqüências negativas para o desempenho da função do professor. Assim sendo, Krug; Krug e Telles (2019) constataram que, a docência em EF na EB comporta sentimentos de frustração profissional.

Também outro 'sentimento negativo' mais citado pelos professores estudados (duas citações - Professores: 1; e, 5), o quinto, foi o ‘desânimo'. Segundo Luft (2000), desânimo é o estado de quem se mostra desanimado, desestimulado. Nesse sentido, Krug; Krug e Telles (2019) constataram que, a docência em EF na EB comporta sentimentos de desânimo profissional. Já, Bianchini et al. (2017, p.360) dizem que, o que preocupa com relação ao sentimento de desânimo "[...] é justamente a falta de ação diante da busca por uma solução". Entretanto, Macedo (2008) destaca que, o sentimento e a ação se relacionam de modo solidário e, portanto os sentimentos desencadeadores e mantenedores dessa ação não estão presentes diante de uma situação onde o desânimo prevalece.

A 'raiva' foi o sexto e último 'sentimento negativo' mais citado pelos professores estudados (uma citação - Professor: 2). Luft (2000) aponta que, a raiva é um sentimento de protesto, insegurança, timidez ou frustração, contra alguém ou alguma coisa, que as pessoas demonstram quando se sentem ameaçadas. Varia de intensidade e de pessoa para pessoa, podendo ser uma simples irritação ou uma demonstração de fúria. Dessa maneira, Krug; Krug e Telles (2019) constataram que, a docência em EF na EB comporta sentimentos de raiva profissional. Entretanto, convém lembrarmos Macedo (2008, p.47) que diz que, o sentimento de raiva pode ser analisado sob o ponto de vista positivo ou negativo. Enquanto afeto positivo "pode significar defesa, proteção ou marcar o desconforto causado por ações, sobretudo se violentas ou inadequadas". Por outro lado, "a raiva de modo negativo afasta, perturba, acentua a dimensão relacional na direção oposta ao que aproxima ou valoriza positivamente". Dessa forma, precisamos ter cuidado especial com o modo negativo do sentimento raiva.

Assim, estes foram os sentimentos vivenciados pelos professores de EF na docência nos Anos Finais do Ensino Fundamental, nas percepções dos professores de EF iniciantes na EB estudados. 
Ao realizarmos uma 'análise geral' sobre as percepções dos professores de EF iniciantes na EB estudados, relativamente aos sentimentos vivenciados na docência nos Anos Finais do Ensino Fundamental, 'identificamos um rol de dez sentimentos vivenciados', sendo quatro classificados como 'positivos' ('alegria'; ‘ânimo'; ‘satisfação'; e, 'gratificação') e seis classificados como 'negativos' ('desânimo'; 'insatisfação'; 'impotência'; ‘frustração'; 'raiva'; e, 'insegurança'). É importante esclarecer que, 'todos os professores estudados vivenciaram sentimentos positivos e negativos' relativos à sua docência nos Anos Finais do Ensino Fundamental. Esse fato está em concordância com o que afirmam Krug; Krug e Krug (2019, p. 87) de que os sentimentos vivenciados pelos professores de EF da EB oscilam "[...] entre sentimentos negativos e positivos [...]" para com a docência.

Nesta 'análise geral' também constatamos que, 'aconteceu à existência de certo antagonismo de sentimentos classificados como positivos e sentimentos classificados como negativos' com todos os professores estudados (Professor 1: dois positivos e quatro negativos; Professor 2: três positivos e três negativos; Professor 3: dois positivos e quatro negativos; Professor 4: quatro positivos e três negativos; e, Professor 5: três positivos e três negativos). Nesse cenário, mencionamos Barreto (2007) que destaca que, o ofício docente está mesclado dos antagonismos inerentes à condição humana; prazer, dor, alegria e tristeza; antagonismo que convivem juntos, dialogam no ato de ensinar e na arte de conviver. É presença constante na vida do professor.

Também podemos constatar que, os 'sentimentos negativos' (seis sentimentos com dezessete citações) vivenciados pelos professores de EF iniciantes na EB estudados foram em 'maior quantidade' que os 'sentimentos positivos' (quatro sentimentos com quatorze citações). Essa constatação possui sustentação em Gatti (2000, p. 62) que destaca que, "as fontes de satisfação são mais reduzidas e delimitadas [...], enquanto as fontes de frustração têm um espectro mais amplo, com atuação mais difusa, porém mais forte pela somatória delas".

\section{AS CONSIDERAÇÕES FINAIS}

Pela análise das informações obtidas constatamos que:

a) Quanto ao papel/função do professor de Educação Física na docência nos Anos Finais do Ensino Fundamental, nas percepções dos professores de Educação Física iniciantes na Educação Básica estudados.

Foi possível 'identificar um rol de três entendimentos' dos professores de EF iniciantes na EB 'sobre o papel/função' do professor de EF nos Anos Finais do Ensino 
Fundamental: 'contribuir na formação da cidadania dos alunos'; 'ser educador'; e, 'transmitir conhecimentos'.

Assim, concluímos que, as percepções dos professores de EF iniciantes na EB estudados, sobre o papel/função do professor de EF na docência nos Anos Finais do Ensino Fundamental, está sustentado em dois pólos de visão da EF na escola e do papel/função do professor frente ao ensino. Um, tendo a EF como transformadora do status quo da sociedade vigente e, outro, tendo a EF como reprodutora do status quo da sociedade vidente.

Desta forma, podemos inferir que, o papel/função do professor de EF nos Anos Finais do Ensino Fundamental precisa ser debatido para que possamos ter uma compreensão mais elaborada deste papel/função, para que novos horizontes sejam explorados para que a EF venha alcançar uma melhoria de sua qualidade no currículo escolar.

b) Quanto aos desafios do professor de Educação Física na docência nos Anos Finais do Ensino Fundamental, nas percepções dos professores de Educação Física iniciantes na Educação Básica estudados.

Foi possível 'identificar um rol de seis desafios' do professor de EF na docência nos Anos Finais do Ensino Fundamental, nas percepções dos professores de EF iniciantes na EB estudados: 'as condições de trabalho difíceis'; 'o isolamento docente'; 'a indisciplina dos alunos'; 'a falta de interesse dos alunos pelas atividades propostas'; 'a inexperiência profissional'; e, 'a desvalorização da EF na escola'.

Assim, concluímos que, as percepções dos professores de EF iniciantes na EB estudados, relativamente aos desafios do professor de EF na docência nos Anos Finais do Ensino Fundamental, estão em maior quantidade 'ligados à estrutura da escola/sistema educacional' seguidos pelos 'ligados aos alunos da EB' e pelos 'ligados aos próprios professores, ou seja, a si mesmos'.

Desta forma, podemos inferir que, os desafios do professor de EF nos Anos Finais do Ensino Fundamental são originados por fatores ligados internamente ao ensino (professor e alunos) ou por aqueles ligados aos fatores ligados externamente ao ensino (estrutura da escola/sistema educacional), mas, no entanto, ambos possuem grande influência sobre o professor e o seu trabalho. Ainda podemos inferir que, o pano de fundo, isto é, o que está por trás dos desafios é a precarização do trabalho docente em EF na EB.

c) Quanto aos sentimentos vivenciados pelo professor de Educação Física na docência nos Anos Finais do Ensino Fundamental, nas percepções dos professores de Educação Física iniciantes na Educação Básica estudados. 
Foi possível 'identificar um rol de dez sentimentos' vivenciado pelo professor de EF na docência nos Anos Finais do Ensino Fundamental, nas percepções dos professores de EF iniciantes na EB estudados, sendo 'quatro classificados como positivos' ('alegria'; 'ânimo'; 'gratificação'; e, ‘satisfação') e 'seis classificados como negativos' ('insegurança'; ‘insatisfação'; ‘impotência'; ‘frustração’; ‘desânimo’; e, 'raiva'). Ainda identificamos que, ‘os sentimentos classificados como negativos foram em maior quantidade do que os sentimentos classificados como positivos'.

Assim, concluímos que, as percepções dos professores de EF iniciantes na EB estudados, a respeito dos sentimentos vivenciados pelo professor de EF na docência nos Anos Finais do Ensino Fundamental, 'mostrou a existência de certo antagonismo de sentimentos classificados como positivos e como negativos com todos os professores estudados'.

Desta forma, podemos inferir que, os sentimentos vivenciados pelo professor de EF na docência nos Anos Finais do Ensino Fundamental, mostram uma ambigüidade se sentimentos, pois o professor pode, em uma mesma aula, vivenciar sentimentos positivos bem como negativos e que essa situação está relacionada com os acontecimentos da própria atuação docente.

Diante deste cenário descrito anteriormente, concluímos que, a docência no INÍCIO DA CARREIRA nos Anos Finais do Ensino Fundamental, nas percepções dos professores de EF iniciantes na EB estudados, mostrou uma realidade educacional COMPLEXA, pois apontou papéis/funções, desafios e sentimentos docentes bem diversificados e, por vezes, contraditórios, o que dificulta a fase de entrada na carreira.

Assim, os resultados desta investigação apontam para a necessidade de mais discussões e estudos sobre a COMPLEXIDADE DA DOCÊNCIA NO INÍCIO DA CARREIRA de professores de EF da EB para que novos horizontes sejam explorados para contribuir com a melhoria da qualidade do ensino desta disciplina na escola, bem como para contribuir em um bom desenvolvimento profissional deste docente.

Para finalizar, destacamos que é preciso considerar que este estudo fundamentou-se nas especificidades e nos contextos de uma cidade em particular e de professores de EF iniciantes na EB em específico e que seus achados não podem ser generalizados e sim encarados como uma possibilidade de ocorrência. 


\section{REFERÊNCIAS BIBLIOGRÁFICAS}

ALVES-MAZZOTTI, A. J. Usos e abusos dos estudos de caso. Cadernos de Pesquisa, São Paulo, v.36, n.129, p.637-651, 2006.

ARAGÃO, P.; MORETTI-PIRES, R.O. Questionários. In: SANTOS, S.G. dos; MORETTIPIRES, R.O. (Orgs.). Métodos e técnicas de pesquisa qualitativa aplicada à Educação Física. Florianópolis: Tribo da Ilha, 2012. p.184-187.

BARRETO, M. da A. Ofício, estresse e resiliência: desafio do professor universitário, 2007. Tese (Doutorado em Educação) - Universidade Federal do Rio Grande do Norte, Natal, 2007.

BEHRENS, M.A. A formação pedagógica e os desafios do mundo moderno. In: MASETTO, M. (Org.). Docência na universidade. 6. ed. Campinas: Papirus, 2003.

BIANCHINI, L.G.B. et al. Sentimentos vivenciados pelo pedagogo em suas interações com os alunos na escola. Rev. Ens. Educ. Cienc. Human., v.18, n.4, p.335-362, 2017.

CARDOSO, S. A relação dialética entre a inserção na carreira e as condições de trabalho docente. Revista Pensar Acadêmico, Manhuaçu, v.18, n.1, p.185-196, jan./abr. 2020.

CASTRO, J.N. de. Educação Física Escolar: uma prática alienada ou transformada?

Possibilidades para uma perspectiva de Educação Física baseada na 'Educação Para o Pensar'. Revista Digital Lecturas: Educación Física y Deportes, Buenos Aires, a.15, n.143, p.1-13, abr. 2010. Disponível em: <https://www.efdeportes.com/efdeportes/index.php/EFDeportes $>$. Acesso em: 6 ago. 2020.

CERVO, A.L.; BERVIAN, P.A. Metodologia científica. São Paulo: Pretince Hall, 1996.

CONCEIÇÃO, V.J.S. da; FRASSON, J.S.; MEDEIROS, C. da R.; WITTIZORECKI, E.S.; KRUG, H.N. A organização escolar e o trabalho docente de professores iniciantes de Educação Física de Criciúma-SC. Revista Pensar a Prática, Goiânia, v.18, n.4, p.769-781, out./dez. 2015.

CONCEIÇÃO, V.J.S. da; KRUG, H.N.; BOROWSKI, E.B.V.; FRASSON, J.S. Formação inicial e a prática inicial e a prática pedagógica do professor de Educação Física iniciante.

Revista Olhar de Professor, Ponta Grossa, v.17, n.1, p.86-97, 2014.

DARIDO, S.C.; NETO, L.S. O contexto da Educação Física na escola. In: DARIDO, S.C.; RANGEL, I.C. (Orgs.). Educação Física na escola: implicações para a prática pedagógica. Rio de Janeiro: Guanabara Koogan, 2005.

FLORES, P.P.; CONTREIRA, C.B.; ILHA, F.R. da S.; CRISTINO, A.P. da R.; KRÜGER, L.G.; KRUG, H.N. O percurso profissional de professores de Educação Física Escolar de Santa Maria, RS. Revista Digital Lecturas: Educación Física y Deportes, Buenos Aires, a.15, n.147, p.1-28, ago. 2010. Disponível em:

$<$ https://www.efdeportes.com/efdeportes/index.php/EFDeportes $>$. Acesso em: 22 maio 2020.

FREIRE, P. Pedagogia da autonomia: saberes necessários à prática educativa. São Paulo: Paz e Terra, 1996. 
GATTI, B.A. Formação de professores e carreira: problemas e movimentos de renovação. 2. ed. Campinas: Autores Associados, 2000.

GAUTHIER, C. et al. (Orgs.). Por uma teoria da Pedagogia: pesquisas contemporâneas sobre o saber docente. Ijuí: UNIJUÍ, 1998.

GOLDENBERG, M. A arte de pesquisar: como fazer pesquisa qualitativa em ciências sociais. 8. ed. Rio de Janeiro/São Paulo: Editora Record, 2004.

HUBERMAN, M. O ciclo de vida profissional dos professores. In: NÓVOA, A. (Org.). Vidas de professores. 2. ed. Porto: Porto Editora, 1995. p.31-61.

ILHA, F.R. da S.; KRUG, H.N. O professor iniciante e a Educação Física Escolar: desafios que se somam. In: CONCEIÇÃO, V.J.S. da; FRASSON, J.S. (Orgs.). Textos e contextos sobre o trabalho do professor de Educação Física no início da carreira. Porto Alegre: Sulina, 2016. p.181-204.

ILHA, F.R. da S.; MASCHIO, V.; KRUG, H.N. A compreensão dos acadêmicos da Licenciatura do CEFD/UFSM sobre as abordagens de ensino da Educação Física. Revista Digital Lecturas: Educación Física y Deportes, Buenos Aires, a.13, n.127, p.1-9, dez. 2008. Disponível em: $<$ http://www.efdeportes.com/efd127/a-compreensao-dos-academicos-dalicenciatura-sobre-educacao-fisica.htm>. Acesso em: 28 jul. 2020.

ILHA, F. R. da S.; IVO, A. A.; KRUG, H. N. Refletindo a prática pedagógica do professor de Educação Física através da organização de suas aulas. In: SEMINÁRIO DE EPISTEMOLOGIA E EDUCAÇÃO FÍSICA ESCOLAR, 2., 2007, Santa Maria. Anais, Santa Maria: CEFD/UFSM, 2007.

KAEFER, R. de C.L.; BOSSLE, F.; FONSECA, D.G. da. "Quando cada caso não é um caso" e quando cada caso é um caso: um estudo de casos etnográficos com professores de Educação Física iniciantes da rede de ensino de Novo Hamburgo. In: CONCEIÇÃO, V.J.S. da; FRASSON, J.S. (Orgs.). Textos e contextos sobre o trabalho do professor de Educação Física no início da docência. Porto Alegre: Sulina, 2016. p.149-180.

KRUG, H.N. A reflexão na prática pedagógica do professor de Educação Física, 1996. Dissertação (Mestrado em Ciência do Movimento Humano) - Universidade Federal de Santa Maria, Santa Maria, 1996.

KRUG, H. N. Comparação das dificuldades encontradas na prática pedagógica em Educação Física de acadêmicos em situação de Estágio Curricular Supervisionado e professores iniciantes na Educação Básica. Revista Gestão Universitária, Belo Horizonte, p.1-13, nov. 2017. Disponível em: <http://www.gestaouniversitaria.com.br/artigos/comparacao-dasdificuldades-encontradas-na-pratica-pedagogica-em-educacao-fisica-de-academicos-emsituacao-de-estagio-curricular-supervisionado-e-professores-iniciantes-na-educacao-basica $>$. Acesso em: 2 jun. 2020.

KRUG, H. N. O papel/função da Educação Física Escolar nos Anos Iniciais do Ensino Fundamental nas percepções dos professores unidocentes. Revista Gestão Universitária, Belo Horizonte, p.1-9, set. 2018. Disponível em: 
$<$ http://www.gestaouniversitaria.com.br/artigos/o-papel-funcao-da-educacao-fisica-escolarnos-anos-iniciais-do-ensino-fundamental-nas-percepcoes-dos-professores-unidocentes $>$. Acesso em: 23 jul. 2020.

KRUG, H. N. Apontamentos sobre as dificuldades na prática pedagógica em Educação Física: o caso dos professores iniciantes. Revista Gestão Universitária, Belo Horizonte, p.1-10, set. 2019a. Disponível em: <http://www.gestaouniversitaria.com.br/artigos/apontamentos-sobreas-dificuldades-na-pratica-pedagogica-em-educacao-fisica-o-caso-dos-professoresiniciantes>. Acesso em: 2 abr. 2020.

KRUG, H. N. As dificuldades na gestão de aula em diversas fases da carreira de professores de Educação Física da Educação Básica. Revista Gestão Universitária, Belo Horizonte, p.113, out. 2019b. Disponível em: <http://www.gestaouniversitaria.com.br/artigos/asdificuldades-na-gestao-de-aula-em-diversas-fases-da-carreira-de-professores-de-educacaofisica-da-educacao-basica>. Acesso em: 21 maio 2020.

KRUG, H. N. Contribuições da Educação Física Escolar na construção da cidadania dos alunos da Educação Básica: percepções de professores da área. Revista Gestão Universitária, Belo Horizonte, p.1-10, fev. 2019c. Disponível em: $<$ http://www.gestaouniversitaria.com.br/artigos/contribuicoes-da-educacao-fisica-escolar-naconstrucao-da-cidadania-dos-alunos-da-educacao-basica-percepcoes-de-professores-da-area $>$. Acesso em: 23 maio 2020.

KRUG, H. N. Apontamentos sobre a fase de entrada na carreira docente em Educação Física: o choque com a realidade escolar. Revista Gestão Universitária, Belo Horizonte, p.1-13, jan. 2020b. Disponível em: <http://www.gestaouniversitaria.com.br/artigos/apontamentos-sobrea-fase-de-entrada-na-carreira-docente-em-educacao-fisica-o-choque-com-a-realidadeescolar>. Acesso em: 2 jun. 2020.

KRUG, H. N. Apontamentos sobre a fase de entrada na carreira docente em Educação Física: o surgimento do entusiasmo profissional. Revista Gestão Universitária, Belo Horizonte, p.112, jan. 2020c. Disponível em: $<$ http://www.gestaouniversitaria.com.br/artigos/apontamentossobre-a-fase-de-entrada-na-carreira-docente-em-educacao-fisica-o-surgimento-doentusiasmo-profissional>. Acesso em: 2 jun. 2020.

KRUG, H. N.; KRUG, R. de R. A indisciplina dos alunos da Educação Básica nas aulas de Educação Física de professores iniciantes na carreira docente. Revista Gestão Universitária, Belo Horizonte, p.1-14, nov. 2019. Disponível em:

$<\mathrm{http}$ ://www.gestaouniversitaria.com.br/artigos/a-indisciplina-dos-alunos-da-educacaobasica-nas-aulas-de-educacao-fisica-de-professores-iniciantes-na-carreira-docente $>$. Acesso em: 21 maio 2020.

KRUG, H. N.; KRUG, R. de R.; KRUG, M.M. Sentimentos vivenciados pelos professores de Educação Física da Educação Básica em suas interações com os alunos. Revista Querubim, Niterói, a.15, n.39, v.2, p.87-96, 2019.

KRUG, H. N.; KRUG, R. de R.; KRUG, M.M. As preocupações pedagógicas de professores de Educação Física iniciantes na Educação Básica. Revista Querubim, Coletânea Biologia e Educação Física, Niterói, a.16, p.43-52, 2020a. 
KRUG, H. N.; KRUG, R. de R.; TELLES, C. Os sentimentos expressos pelos professores de Educação Física da Educação Básica frente às dificuldades da prática pedagógica. Revista Biomotriz, Cruz Alta, v.13, n.2, p.49-68, jun. 2019.

KRUG, H. N.; CONCEIÇÃO, V. J. S. da; KRUG, H.N.; TELLES, C. A complexidade da docência nos Anos Iniciais do Ensino Fundamental: a percepção dos acadêmicos de Educação Física em situação de Estágio Curricular Supervisionado. Revista Série-Estudos, Campo Grande, n.39, p.117-136, jan./jun. 2015.

KRUG, H. N.; ANTUNES, F. R.; MAZZOCATO, A. P. F.; CARAMÊS, A. de S.; CASSAROTTO, V. J. Os sentimentos expressos pelos acadêmicos da Licenciatura em Educação Física do CEFD/UFSM durante a experiência docente no Estágio Curricular Supervisionado. Revista Digital Lecturas: Educación Física y Deportes, Buenos Aires, a.17, n.172, p.1-7, set. 2012. Disponível em: <https://www.efdeportes.com/efd172/ossentimentos-expressos-pelos-academicos.htm>. Acesso em: 21 maio 2020.

KRUG, H. N.; KRUG, M. de R.; KRUG, R. de R.; TELLES, C.; FLORES, P.P. Os desafios do cotidiano educacional de professores de Educação Física iniciantes na Educação Básica. Revista Didática Sistêmica, Rio Grande, v.19, n.2, p.14-28, $2017 \mathrm{a}$.

KRUG, H. N.; KRUG, R. de R.; KRUG, M. de R.; TELLES, C.; FLORES, P.P. As marcas docentes no início da carreira de professores de Educação Física na Educação Básica. Revista Triângulo, Uberaba, v.10, n.1, p.56-72, jan./jun. 2017b.

KRUG, H. N.; KRUG, M. de R.; KRUG, R. de R.; TELLES, C.; FLORES, P.P. As contribuições da formação inicial para a prática docente na percepção de professores de Educação Física iniciantes na Educação Básica. Revista Querubim, Niterói, a.13, n.33, v.02, p.104-109, 2017c.

KRUG, H. N.; KRUG, M. de R.; KRUG, R. de R.; KRUG, M. M.; TELLES, C. As representações sociais de educação escolar e Educação Física Escolar de professores da área na Educação Básica. Revista Querubim, Niterói, a.14, n.36, v.03, p.52-60, 2018.

KRUG, H. N.; KRUG, R. de R.; KRUG, M. de R.; KRUG, M. M.; TELLES, C. Necessidades formativas de professores de Educação Física iniciantes na Educação Básica. Revista Querubim, Niterói, a.15, n.38, v.4, p.23-31, 2019a.

KRUG, H. N.; KRUG, R. de R.; KRUG, M. de R.; KRUG, M. M.; TELLES, C. As dificuldades pedagógicas em diversas fases da carreira de professores de Educação Física na Educação Básica. Horizontes - Revista de Educação, Dourados, v.7, n.13, p.223-246, jan./jun. 2019b.

KRUG, H. N.; KRUG, M. de R.; KRUG, R. de R.; KRUG, M. M.; TELLES, C. A docência em Educação Física na Educação Básica: os fatores indicativos de (in)satisfação profissional em diferentes fases da carreira. Revista Querubim, Niterói, a.15, n.38, v.4, p.13-22, 2019c.

KRUG, H. N.; KRUG, M. de R.; KRUG, R. de R.; KRUG, M. M. A Educação Física na Educação Básica: os fatores indicativos de (des)valorização em diferentes fases da carreira. Revista Unifamma, Maringá, v.19, n.1, 2020. (No Prelo). 
KRUG, R. de R.; KRUG, H. N. As gratificações e frustrações da docência em Educação Física Escolar para os acadêmicos do CEFD/UFSM em situação de estágio. Revista Digital Lecturas: Educación Física y Deportes, Buenos Aires, a.13, n.125, p.1-10, oct. 2008. Disponível em: $<$ https://www.efdeportes.com/efdeportes/index.php/EFDeportes $>$. Acesso em: 23 maio 2020.

LIMA, E.F. de (Org.). Sobrevivência no início da docência. Brasília: Líber Livro Editora, 2006.

LIMA, V. M. M. A complexidade da docência nos anos iniciais na escola pública. Revista Nuances: Estudos Sobre Educação, Presidente Prudente, a.XVIII, v.22, n.23, p.151-169, mai./ago. 2012.

LUCKESI, C. C. Filosofia da educação. São Paulo: Cortez, 1992.

LUFT, C.P. MiniDicionário Luft. São Paulo: Ática/Scipione, 2000.

MACEDO, L. Para uma psicopedagogia construtivista. In: ALENCAR, E.S. (Org.). Novas contribuições da Psicologia aos processos de ensino e aprendizagem. São Paulo: Cortez, 2008.

MARCOLAN, S.G. et al. Docência: fatores indicativos de insatisfação na contemporaneidade. Revista Agora, n.25, p.84-96, dez. 2017.

MARQUES, M. N.; CRISTINO, A. P. da R.; ILHA, F. R. da S.; KRUG, H. N. Os desafios da prática pedagógica na Educação Física Escolar para a construção da cidadania. In:

CONGRESSO INTERNACIONAL DE EDUCAÇÃO POPULAR E SEMINÁRIO

INTERNACIONAL DE EDUCAÇÃO POPULAR, 9., 18., 2009, Santa Maria. Anais, Santa Maria: MOBREC, SMEd-Santa Maria, 2009.

MARQUES, M. N.; KRUG, R. da R.; KRUG, H. N.; CONCEIÇÃO, V. J. S. da. Os desafios do cotidiano educacional: o caso da Educação Física. Revista Roteiro, Joaçaba, v.40, n.1, p.187-206, jan./jun. 2015.

MATTOS, M.G. de. Vida no trabalho e sofrimento mental do professor de Educação Física da escola municipal: implicações em seu desempenho e na vida profissional, 1994. Tese (Doutorado em Administração Escolar) - USP, São Paulo, 1994.

MEDEIROS, C. da R.; BOROWSKI, E. B. V.; KRUG, H. N.; CONCEIÇÃO, V. J. S. da. Identização docente de professores de Educação Física no início da carreira. Revista Educação em Perspectiva, Viçosa, v.5, n.2, p.31-49, jul./dez. 2014.

MEDINA, J. A Educação Física cuida do corpo... e mente. Campinas: Papirus, 1983.

MINAYO, M. C. de S.; DESLANDES, S. F.; GOMES, O. C. N. (Orgs.). Pesquisa social: teoria, método e criatividade. Petrópolis: Vozes, 2007.

MOLINA NETO, V. Etnografia: uma opção metodológica para alguns problemas e investigação no âmbito da Educação Física. In: MOLINA NETO, V.; TRIVIÑOS, A. N. S. 
(Orgs.). A pesquisa qualitativa em Educação Física: alternativas metodológicas. 3. ed. Porto Alegre: Sulina, 2010. p.113-146.

NOAL, I. K. Manifestações do mal-estar docente na vida de professoras do Ensino Fundamental: um estudo de caso, 2003. Dissertação (Mestrado em Educação) Universidade Federal de Santa Maria, Santa Maria, 2003.

PIMENTA, S. G. Formação de professores: identidade e saberes da docência. In: PIMENTA, S. G. (Org.). Saberes pedagógicos e atividade docente. 4. ed. São Paulo: Cortez, 2005.

QUADROS, L. R. de; CARDOSO, V. D.; FRASSON, J. S.; MEDEIROS, C. da R.; BOROWSKI, E. B. V.; CONCEIÇÃO, V. J. S. da; KRUG, H. N. O trabalho docente de professores de Educação Física iniciantes do município de Criciúma-SC. Revista Conexões, Campinas, v.13, n.3, p.12-23, jul./set. 2015.

QUADROS, Z. de F.; BLASIUS, J.; KRUG, H. N.; CONCEIÇÃO, V. J. S. da. Prática educativa de professores de Educação Física no início da carreira. Revista Educação \& Linguagem, São Paulo, v.18, n.1, p.21-40, jan./jun. 2015.

REZER, R.; MADELA, A.; DAL-CIN, J. Apontamentos sobre o ingresso na carreira docente: possibilidades para o campo da Educação Física. In: CONCEIÇÃO, V. J. S. da; FRASSON, J.S. (Orgs.). Textos e contextos sobre o trabalho do professor de Educação Física no início da docência. Porto Alegre: Sulina, 2016. p.65-84.

SANTOS, M. dos; CONCEIÇÃO, V. J. S. da; FRASSON, J. S.; KRUG, H. N. Dificuldades pedagógicas encontradas por professores de Educação Física no início da docência. Revista Querubim, Niterói, a.12, n.28, v.03, p.32-38, 2016.

SOUZA, R.R. de. Contribuição da disciplina de Educação Física para a formação da cidadania. In: FOLLE, A.; FARIAS, G.O. (Orgs.). Educação Física: prática pedagógica e trabalho docente. Florianópolis: Editora da UDESC, 2012. p.239-259.

TARDIF, M. Saberes docentes e formação profissional. 2. ed. Petrópolis: Vozes, 2002.

TELLES, C.; KRUG, R. de R.; CONCEIÇÃO, V. J. S. da; KRUG, H. N. Os saberes necessários ao bom professor de Educação Física Escolar na percepção dos acadêmicos ingressantes da graduação. Revista Gestão Universitária, Belo Horizonte, p.1-14, mar. 2015. Disponível em: http://www.gestaouniversitaria.com.br/artigoscientificos/os-saberesnecessarios-ao-bom-professor-de-educacao-fisica-escolar-na-percepcao-dos-aca... . Acesso em: 23 maio 2020.

TURATO, E. R. Tratado de metodologia da pesquisa clínico-qualitativa: construção teórico-epistemológica, discussão comparada e aplicação nas áreas da saúde e humanas. 2. ed. Petrópolis: Vozes, 2003.

WEISINGER, H. Inteligência emocional no trabalho. Rio de Janeiro: Objetiva, 1997. 